\title{
Microbiological Assessments in a Cut Flower Crop Polytunnel Field Trial Adopting Soil Covering and Microbiocides for Fusarium Wilt Suppression
}

\author{
JR. Rao, David Nelson, Colin Fleming, Trevor Martin
}

\section{ABSTRACT}

Cut flower Matthiola incana were raised by local commercial cultivators in a polytunnel. The field soil beds were either left uncovered as normal or covered with polythene sheets (except a hole for plant plug space). Average temperatures in the top $5 \mathrm{~cm}$ soil under cover dropped from $28^{\circ} \mathrm{C}$ to $18{ }^{\circ} \mathrm{C}$ compared to its spiking up to $37^{\circ} \mathrm{C}$ in uncovered counterparts. Microbiological analyses indicated that soil covering induced two $\log _{10}$ folds reduction of the wilt causal fungi Fusarium oxysporum and concomitantly increased one $\log _{10}$ fold wilt antagonistic natural soil inhabiting fungi populations. Standard dip/drench mixtures of commercial and local isolates microbiocides (bacteria) applied to $M$. incana plug roots improved plant health assessed by visible scores of the level of damage or wilt symptoms under soil covered treatments. Scanning electron microscopy, cultural and 16S rRNA PCR analyses revealed potent antifungal bacteria attached to the hyphal surfaces of $F$. oxysporum as ectosymbionts that may have implications for virulence regulation and host plants' wilt disease control. Our microbiological data support the prospects of combining physiological and microbiological interventions upon covering the soil surface that offers the local horticulturists an evidence based sustainable means of Fusarium wilt control suppression in polytunnel crops.

Keywords: Microbiocides, Mathiola incana, light/temperature modulation, disease control.
Published Online: September 4, 2020

ISSN: 2684-5199

DOI : $10.24018 /$ ejbio.2020.1.5.70

\section{JR. Rao*}

Agri-Food \& Biosciences Institute, UK.

(e-mail: jr.rao@afbini.gov.uk)

David Nelson

Agri-Food \& Biosciences Institute, UK

(e-mail: david.nelson@afbini.gov.uk)

Colin Fleming

The Queen's University of Belfast, UK.

(e-mail: colin.fleming@afbini.gov.uk)

Trevor Martin

Agri-Food \& Biosciences Institute, UK

(e-mail: trevor.martin@afbini.gov.uk)

*Corresponding Author

\section{INTRODUCTION}

Fusarium wilt of ornamental plants such as Brompton Stock (M. incana), Carnation (Dianthus) and Narcissus important in the cut-flower market in Northern Ireland and is the most frequently encountered glasshouse, polytunnel (polythene covered tunnel) raised crop disease, followed by other soil-borne phytopathogens Pythium and Rhizoctania [1] on the basis of their host specificity causing crown, root rots and vascular wilts. Fusarium wilt disease control measures pose a formidable challenge to the glasshouse crops industry [2] due to stringent Europe-wide pesticide usage regulations, high costs, environmental, human and soil health impact. The sustainable biological alternatives [3] for Fusarium wilt control include soil drenches, root dips of commercial microbiocides (Serenade Max, Prestop), mycoparasitic fungi Clonostachys rosea [4]. Northern Ireland cut flower growers also adopt spent compost dressings and crop rotation to mitigate the flower plants wilt, by planting wilt resistant racespecific [5] varieties lettuce (Lactuca sativa) providing extra farm revenue during off-flower[6]. Subsequently, the flower grower observed (personal communication) surprisingly, visible healthy looking cut flower crop in randomly polythene sheet covered polytunnel field soil plots.

Normally soil coverings in an open filed render rise in subsoil temperature, promote seed germination, prevent avian menace and increase surface saprophytic fungal populations. However, in a polytunnel, the covering of soil in local flower crops suggests light, temperature lowering environmental effects usually associated with circadian clock signal modifications that tend to regulate fungal development, in particular those of $F$. oxysporum [7] in the critical plant stem base/soil microbiome zones [8], [9]. However, despite the above valuable literature background, core microbiological supportive data in the stem wilt infection zone concomitant to the covering of soils under polytunnel field conditions are scarce. In this study, prompted by the flower grower's visible observations on healthy looking plants discovered by chance in plots with soil covering, we set out to seek the microbiological premise, and investigate the physiological on-field (soil covering) manipulation, and the scientific outlook for such practicable and grower adaptable steps in enhancement of disease management of the opportunistic soil phytopathogen $F$. oxysporum, affecting cut flower crops, such as $M$. incana.

\section{Materials And MethodS}

\section{A. Polytunnel field trial}

Using field soil covered by the polytunnels of one of the local cut-flower growers (Greenisland Flowers Co. Armagh, 
Northern Ireland, BT62 1XB), the effects of covering the soil with polythene sheets upon the suppression of the wilt phytopathogen $F$. oxysporum were investigated. The soils were either left uncovered or covered in heavy gauge polythene sheets. Plug plants of 2 cultivars of M.incana (as supplied to local flower growers by a stockist based in The Netherlands) commonly grown locally were included for this study. The flower grower procured and applied the normal crop production and protection measures, including commercial bacterial formulation Serenade Max (Bacillus subtilis QST713) as a standard fungicidal treatment (applied as per manufacturers' instructions) to plug-plants, growing either under covered or uncovered soils. Alternatively, the plug-plants were either dipped or drenched with a cocktail of wilt suppressant native bacteria (Table 1) and held in our laboratory archives as inhibitory bacteria series (IB) viz., IB6/IB12-B. amyloliquefaciens and IB9-Paenibacillus polymyxa isolated from Fusarium infected flower grower's soil in Northern Ireland, UK. Freeze -dried aliquots of IB cocktail mix were also applied at the same rate as Serenade Max.

TABLE 1: LIST OF ORGANISMS USED IN THIS STUDY

\begin{tabular}{ll}
\hline Organism & \multicolumn{1}{c}{ Source } \\
\hline Fusarium species & $\begin{array}{c}\text { Plant Pathology laboratory } \\
\text { culture collection, AFBI, } \\
\text { Newforge Lane, Belfast, UK }\end{array}$ \\
$\begin{array}{l}\text { F. equiseti } \\
\text { F. culmorum }\end{array}$ & \\
$\quad$ Wilt causal agents & LGC Standards, Teddington, \\
F. oxysporum 16602 (Type strain) & Middlesex, UK \\
$\begin{array}{l}\text { F. oxysporum 16603 (Type strain) } \\
\text { F. oxysporum (cured derivative) }\end{array}$ & \\
Other significant soil fungi & \\
Gliocadium spp & \\
Clonostachys rosea & \\
Eurotiomyces spp & \\
Trichoderma citrinoviride & Plant Pathology laboratory \\
Trichoderma atroviride & culture collection, AFBI, \\
Clonostachys pseudochrolueca & Newforge Lane, Belfast, UK \\
Inhibitory Bacteria (IB) & \\
B. amyloliquefaciens & \\
$\begin{array}{l}\text { Paenibacillus polymyxa } \\
\text { Bacillus subtilis QST713 }\end{array}$ & IB6, IB12 (AFBI, Belfast) \\
\hline
\end{tabular}

\section{B. Plant health scores}

Scores of plant health were based on the level of damage or wilt observed: $1=($ no damage $), 2=(10 \%), 3=(11-25 \%)$, $4=(26-50 \%), 5=(100 \%$ dead $)$. F. oxysporum counts were obtained for soils under both covered and uncovered conditions. The soil surface and Matthiola host-plant root systems (MHPRS) temperatures at c. $3.0 \mathrm{~cm}$ to $5.0 \mathrm{~cm}$ depth were recorded using thermal probes (Tinytag data-logger device: http://www.geminidataloggers.com/) using software compatible for data processing via a personal computer (pc). Soil moisture was maintained as per the flower growers' recommendations.

\section{Microbiological investigations}

1. Isolation of wilt fungi and competing antagonistic fungi from flower bed soil

The list of organisms used in this study are described in Table1. Fusarium genera wild type fungal colonies were normally distinguishable in Potato Dextrose agar (PDA) plates due to their distinctive colour and hyphal features (white-mild pink hypal extensions, intense carmine red pigmentation). Other fungi and bacteria co-occurring as adjacent colonies on the same agar plates exhibiting antagonistic zones against presumptive Fusarium colonies on PDA were carefully subcultured for further studies. Type collection cultures of Fusarium oxysporum $f$. sp. mathiolii (16602 and 16603) were obtained from LGC Standards, Teddington, Middlesex, UK for molecular comparisons with wild-type isolates.

2. Isolation of fungal hyphae surface resident bacteria, scanning electron microscopy and molecular assays

Stem sections of putatively infected $M$. incana were surface sterilized and then placed on PDA. The emergent hyphae were serially subcultured a minimum of three times onto fresh PDA. These purified Fusarium WT were examined to check for any co-colonising bacterial cultures adherent to the hyphae (as the presence of a glossy slime) These bacteria were carefully isolated and single-colony purified on LB agar for further molecular analyses. The presence of bacterial ectosymbionts on hyphae of WT Fusarium was further examined via Scanning Electron Microscopy (SEM). PCR assays for the amplification of either fungal 18S rDNA ITS regions, or 16S rRNA universal bacterial amplicons were employed to establish the identity of WT Fusarium morpho-types and those of the hyphal surface bacteria respectively. The resulting PCR amplicon sequences obtained for both the fungal and bacterial samples were established from chromatogram analysis [10] and the confirmed set of sequences were compared with those stored in the GenBank using the BLASTn alignment software (http://www.blast.genome.ad.jp/).

3. Effect of temperature on in vitro growth vigour of Fusarium spp.

From stock Fusarium species cultures $6 \mathrm{~mm}$ diameter plugs were excised and transferred individually to the Cartesian coordinate centre of four directional segments marked previously using a fine-tip marker pen of fresh plates of PDA, incubated for 3 days at ambient temperature to facilitate natural contours of hyphal growth to advance. Once the culture plug establishes, the plates were incubated at temperatures viz., $4^{\circ} \mathrm{C}, 10^{\circ}-15^{\circ} \mathrm{C}, 16^{\circ}-19^{\circ} \mathrm{C}$ (ambient), $20^{\circ}$ $35^{\circ} \mathrm{C}$ ) reflecting the spectrum of Poly tunnel canopies and soil thermal dynamics known in Northern Ireland. The culture plates were examined using a binocular microscope and the outline of the perimeter of the hyphae was carefully traced by marker pen. At 3-day intervals, the extent of the hyphal growth $(\mathrm{mm})$ was marked up to 3 weeks. The final area covered by each culture was measured using the bio-imaging technique [11] to assess growth vigour using the Autochemisystem UVP Bioimaging system (UVP Products, Cambridge, UK), supported by LabWorks software package. Initially the instrument was set on white light and to an exposure ratio of 490:500, with a constant focus of $47 \%$ calibration. Using the "Area Density" tool, (in pixels) the 
entire 'area of individual plate' was measured first, recorded, and then using freehand 'draw' tool followed on by the 'area of irregular contours' of fungal growth co-integrated within the Cartesian coordinates to give an accurate estimate of the in vitro growth intensity of Fusarium species set against the challenge of temperature regimes during their incubation.

\section{Statistical analyses}

The arbitrary ratio, fungal growth, was calculated for each treatment as the ratio of total surface area occupied by fungal growth/total surface area of the petri dish. Statistical analyses

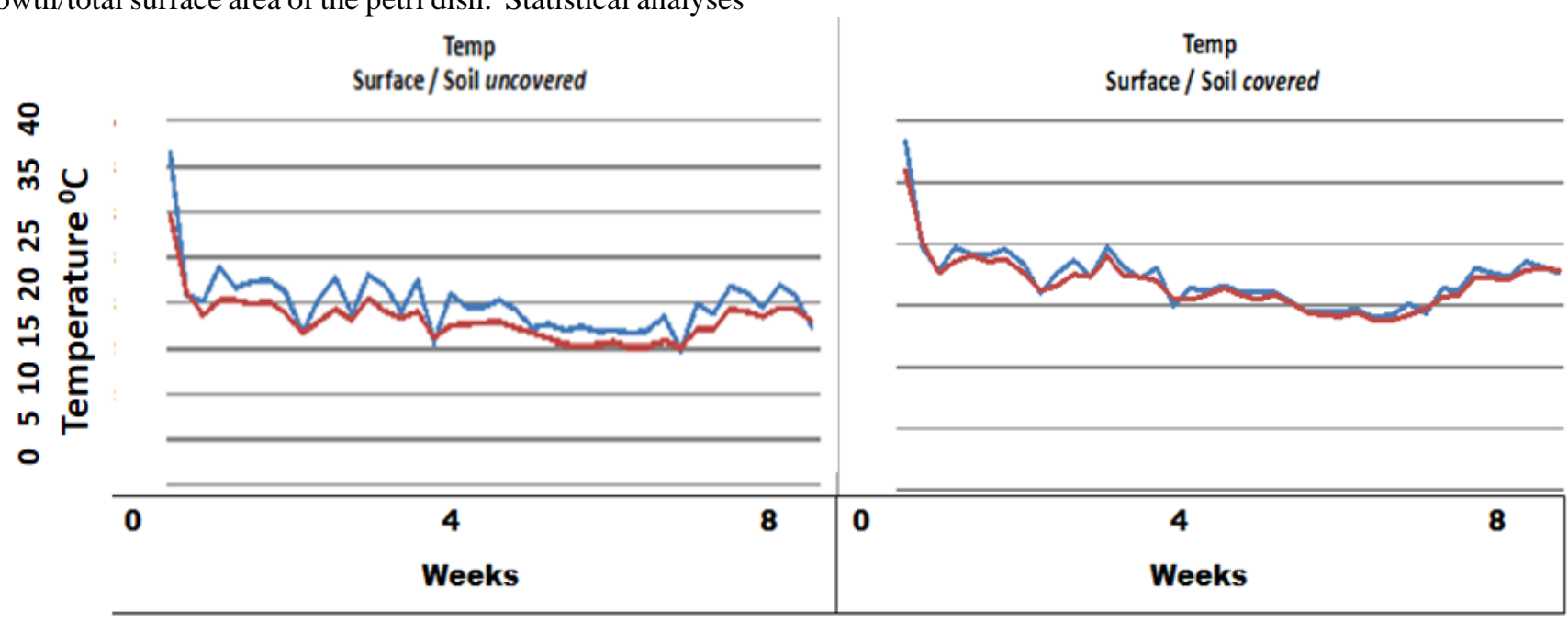

Fig. 1. Temperature gradient recorded over 8 weeks after Mathiola plug transplant into covered and uncovered poly tunnel field soils. Thermal ramp recordings of surface and subsurface $(3.0-5.0 \mathrm{~cm}$ deep) soils just closest to Mathiola incana plant plug stem base / emerging root zone (MPHRZ) in uncovered or polythene sheets covered regimes in poly tunnel field cultivation system.

The temperature ramps recorded over a 8-week period when the soil surface was covered with the polythene sheets showed (Fig. 1) a dramatic drop from $28^{\circ} \mathrm{C}$ to $18^{\circ} \mathrm{C}$ within the first week of plant growth, and after flux of $\pm 2{ }^{\circ} \mathrm{C}$ for the next weeks, the temperature dipped down to $14^{\circ} \mathrm{C}$ for the ensuing 4 weeks before normalising at $18^{\circ} \mathrm{C}$ for surface to root depth layer up to $5 \mathrm{~cm}$ deep. The relative sharp dip in the temperature, by a margin of over $10-14{ }^{\circ} \mathrm{C}$ during the crucial phase of $M$. incana host plug plant establishment, is also important for the growth and proliferation of the saprophyte wilt causal agent $F$. oxysporium. As such, it is a critical time window for host-pathogen interaction. On the other hand, in the uncovered soils, while the surface ambience also had initial fall in temperature from a maximum of \pm 37 ${ }^{\circ} \mathrm{C}$ down to $28{ }^{\circ} \mathrm{C}$, the soil bed beneath had an average of $24^{\circ} \mathrm{C}$; the surface ambient temperature and the MHPRZ $(5 \mathrm{~cm}$ deep) soil in covered state were divergent throughout the first 8 -week period recorded and lacked any normalisation of the two thermal ramps compared to the synchronisation and harmony found in temperature gradient in the surface versus underground $5 \mathrm{~cm}$ deep covered soil. Increased symptoms of wilt in Chrysanthemum morifolium when cultivated in higher temperature $\left(>24^{\circ} \mathrm{C}\right)$ in greenhouses in the USA [12] during summer seasons have been a well-known phenomenon; symptoms became more severe when temperatures $\geq 27{ }^{\circ} \mathrm{C}$, such as those recorded in our studies on $M$. incana cut flower plantlets raised in polytunnels in Northern Ireland. The apparent divergent patterns of thermal flux between the covered and uncovered soil environment could have impacted the population dynamics of the emergent fungi colonising the plug plant host (M. incana) roots. on microbiological and plant health investigations were performed employing the student t-test and values $>0.05(5 \%)$ was considered not significant.

\section{RESUlts AND DISCUSSION}

A. Soil covering and its influence on subsoil temperature flux

\section{B. Plant health evaluations: effects of soil covering and application of microbiocides}

Two cultivars CV1 and CV2 of Matthiola incana (supplied to the flower grower as plug plants by a stockist based in The Netherlands). Scores of plant health were based on the level of damage or wilt observed: $1=($ no damage $), 2=(10 \%), 3=(11-$ $25 \%), 4=(26-50 \%), 5=(100 \%$ dead $)$. Error bars indicate the standard deviations of the mean.

Plant health scores (Fig. 2) showed the percentage of plants compared to their score damage per treatment and cultivar (CV1, CV2) variations against covered and uncovered regimes. Plants with covered roots generally exhibited higher number of plants with less damage when the bacterial treatments were administered as a plug drench, while in uncovered plants, a wider range of symptoms were apparent on visible scores basis. Both covered and uncovered plants secured better and higher scores when a drench treatment followed a dipped mode of treatment before planting the plug plants in the pots. For example, when plants were uncovered regardless of the mode of bacterial pre-treatment (dipped or drenched) or post treatment, over $60 \%$ of CV2 plants had only $10 \%$ damage, whereas over $30 \%$ of CV1 had $10 \%$ damage. However, in the case of soil covered plants, drenched method of pre-treatment of plugs showed CV2 plants had only succumbed to $10 \%$ of wilt damage, whereas over $60 \%$ of CV1 had $10 \%$ damage. Control treatments in general which received no bacterial treatment had a higher number of plants $(\geq 10 \%$ ) with wilt damaged appearance. Overall visible scores indicated that plug plants grown under covered soil seemed to be healthier plants and showed more vigour. The covered treatment scores were generally lower (less damage to plants) 
therefore the differences between treatments and control (no microbiocides) was less. However, in the uncovered treatments, plants were either dead or dying $(\geq 5)$ and there were more overall variations in scores $(\geq 2)$. From the visual observations it can be seen the covered plants look healthier and bigger than the uncovered.

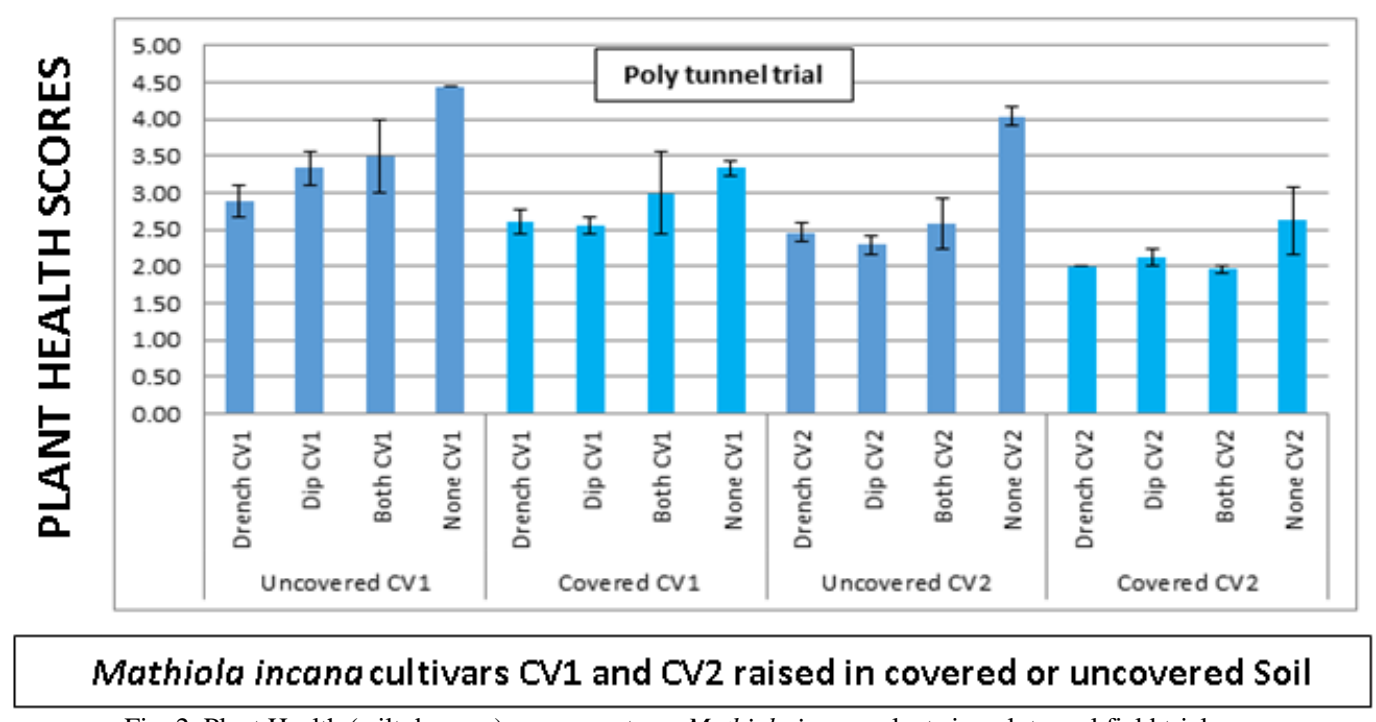

Fig. 2. Plant Health (wilt damage) assessments on Mathiola incana plants in polytunnel field trial.

Our preliminary visible scores data upon plant health (Fig. 2) also heralds the importance of circadian influence on fungal pathogenesis which corroborates those of several researchers who have highlighted the regulation of growth, metabolism, and biotic and abiotic stress resistance responses to light upon a number of fungal pathogens including Fusarium spp [13], Aspergillus spp [14], Phytophthora spp [15]. Our results also heightens the need for utilizing natural physiological tools (e.g. covering the soils around the stem base and roots) as a practical supplementary means for enhanced suppression of the wilt pathogens in tandem with current trends of biological control measures of dipping or drenching treatments (e.g. microbiocides) of plant plugs in field conditions. The systemic toxin theory [16] considers that toxins, (such as fusaric acid produced by $F$. oxysporum) disturb the metabolism of the infected host plant, resulting in leaf wilt with a consequent reduction in root growth, leading to apoptosis, necrosis, and even death. However, in our experiment, our primary goal insofar as heat and light effects are concerned was to evaluate the overbearing influences that the soil covering manipulation has, on the saprophytic soil inhabiting $F$. oxysporum in the soil surface and Matthiola host-plant root systems (MHPRS) before it penetrates the host plant cells.

\section{Effect of temperature on in vitro growth of Fusarium species}

Our preliminary experiment (Fig. 3) to gauge the effect of temperature on in vitro growth vigour of Fusarium spp. in PDA plates incubated in temperature gradients viz., $\left(4^{\circ} \mathrm{C}, 10\right.$ ${ }^{\circ} \mathrm{C}-16{ }^{\circ} \mathrm{C}$ (ambient), $19{ }^{\circ} \mathrm{C}$ (mean annual polytunnel temperature in local flower growers yards), $25{ }^{\circ} \mathrm{C}-35{ }^{\circ} \mathrm{C}$ (polytunnel in this study)) indicated that local native Fusarium spp. were heat sensitive and their growth vigour significantly $(\mathrm{P}=0.005)$ varied sharply, based on the temperature of their environment. In our study, we covered the soils with polythene to simulate a physiological effect of induced light, temperature as compensates of environmental (hidden) factors in air or immediate underground beneath the soil [17].

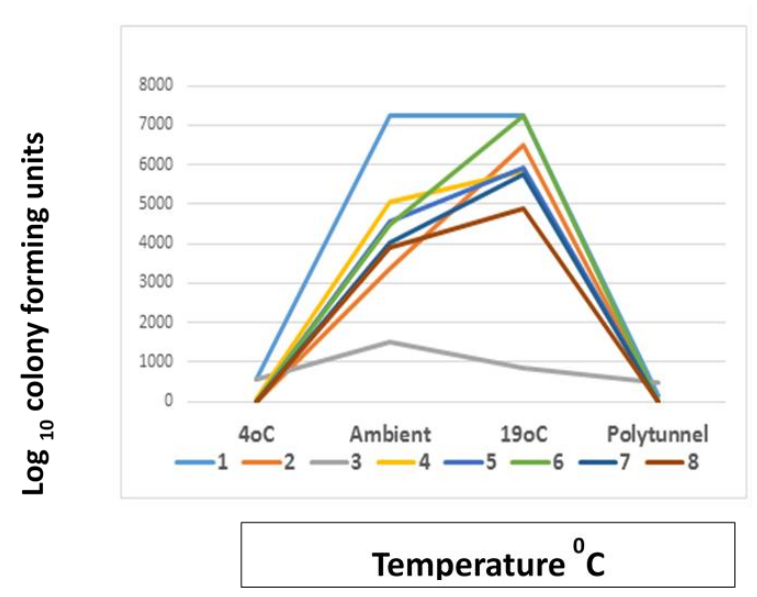

Fig. 3. Effect of temperature on in vitro growth vigour of Fusarium spp.

It is thus perceivable from our generic experimental results presented in this study, the 'light' perception of host ( $M$. incana) canopy above the ground would be the same for covered or uncovered soils, However, for sessile saprophytic fungi such as Fusarium spp, it is critical for the saprophytic mycota to especially evade the substrate in the harsher temperatures prevalent in top surface soil and either head beneath in the competitive substrate-rich root rhizosphere, or produce spores for spreading in the soil/plant interface (e.g emerging stem area near top soil) environment for expressing a temperature modulated opportunistic pathogenicity, as it is apparently the case in $M$. incana stem wilt disease development. Thus, lowering of temperature at this critical soil-plant interface (MHPRZ) will limit the progress of fungal growth and development and besides the ensuing physiological (light, temperature modulated) molecular plant-pathogen interactions.

\section{Microbiological assays}

The soil samples were obtained from a local flower grower's farm (Greenisland Flowers, Co Armagh, Northern 
Ireland) and Fusarium spp. amongst other fungi were isolated from soil collected from polytunnel which had a history of Fusarium infestation of $M$. incana. The soil sampling was carried out closest to the plug plant roots and the stem base where wilt damage was most evident, when the plug-plant transplants were 3-4 weeks old. Concomitantly, a piece of infected stem tissue of $M$. incana which had been surface sterilised and then placed on PDA yielded emergent presumptive Fusarium hyphae from infected tissue. Soil samples taken from closest to the base of the stem and emerging Matthiola host plant root zone (MHPRS) yielded a mixed population of bacterial and fungal colonies on PDA plates (Fig. 4 a). On certain of these plates there was evidence of inhibition of fungal growth, due to bacterial antagonism of the expansion of the hyphae (data not shown]. Single purified Fusarium colonies were incubated and plates with fungal hyphae swarmed by bacterial satellite colonies were retained.
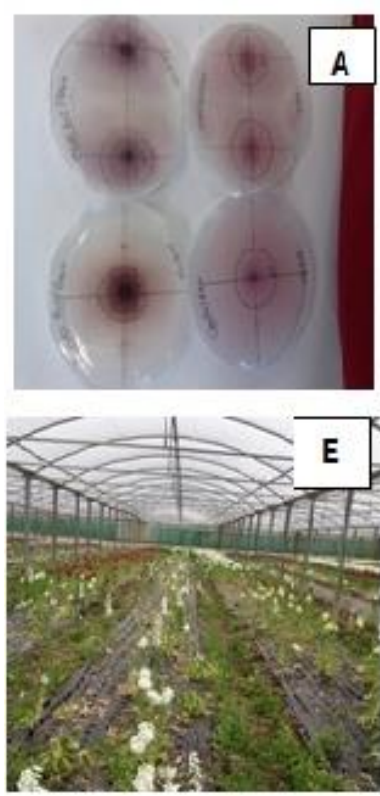
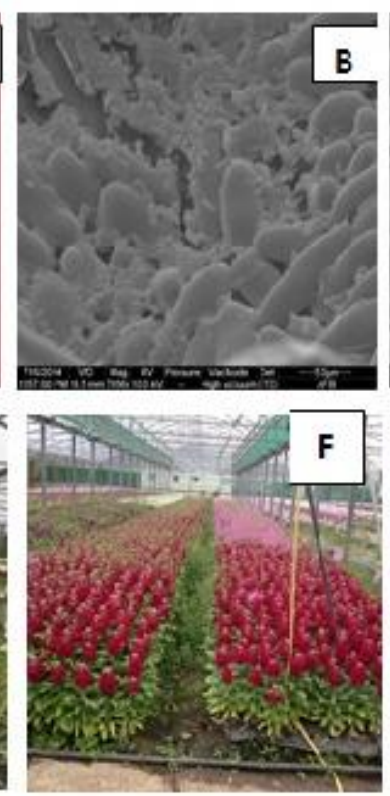
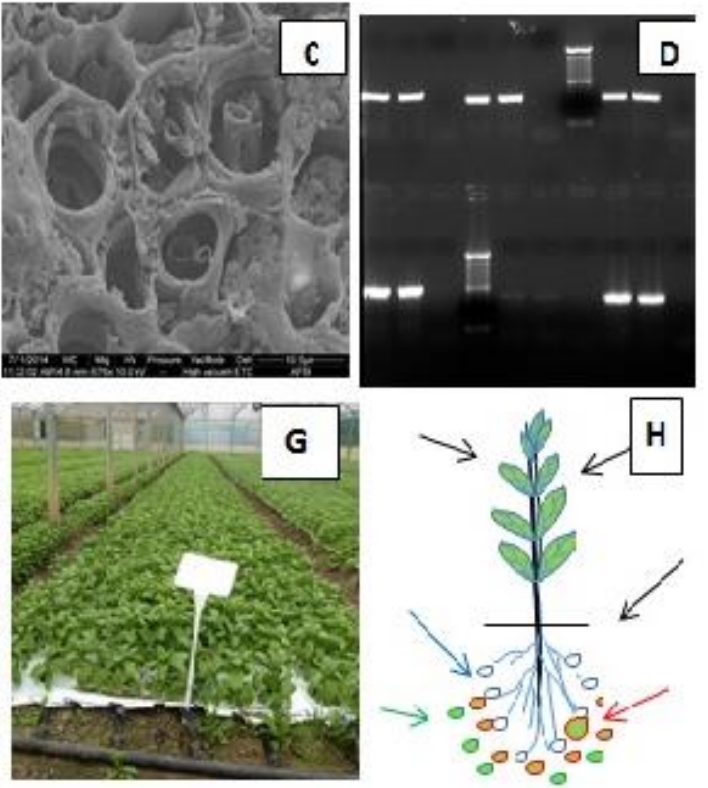

Fig. 4. Isolation and identification of bacterial ectosymbionts on Fusarium oxysporum hyphae.

Ectosymbiont bacteria colonising Fusarium hyphae and their influence on disease expression:

Top Row: Swarms of bacteria emerge from Fusarium oxysporum hyphae isolated from infected stem (A). Scanning Electron Micrograph (SEM) (B). Wilt causal Fusarium oxysporum hyphae seen proliferating in Xylem structures (C) characteristic of wilt pathogenesis. PCR analyses demonstrating the Fusarium oxysporum hyphae carrying ectosymbiont $P$. polymyxa (D).

Bottom row: Effects of soil covering on the cut flower Mathiola incana cultivated in a polytunnel: Two cultivars (CV1 and CV2raised in uncovered or covered soil beds (E) and received no crop protection treatment (control). The emerging healthy looking Mathiola plant (F) under covered soils (G). The encircled red zone highlights an example of bacterial ectosymbionts on fungal hyphae in mycosphere. Such mycosphere fungal-bacterial interactions are present near the stem base (right) - left arrow pointing towards horizontal black line $(\mathrm{H})$.

\section{E. Scanning Electron Microscopy (SEM)}

The Fusarium hyphae obtained from the infected tissue were transferred on to fresh PDA plates, following which bacterial colonies were visible surrounding the emergent mycelial hyphae. Scanning electron microscopy (SEM) of the fungal hyphae from these culture plates revealed the presence of ectosymbiotic rod-shaped bacteria (Fig. 4 b, c) attached to the wilt pathogen Fusarium oxysporum hyphae (obtained via the wilt disease prone Mathiola incana infected tissue). Interestingly Paenibacillus polymyxa, was amongst potent antifungal native bacteria isolated from our previous study alongside Bacillus subtilis and B. amyloliquefaciens; all three of which were demonstrated in vitro [18] for their efficacy to act as natural alternative microbial source for wilt control in floriculture. The generic physiological mechanisms of the pathological wilting of higher plants [19] are generally attributed to xylem or phloem vessel plugging and/or systemic toxicity. The plugging theory indicates that the vascular vessels of infected plants are obstructed by fungal hyphae, thus limiting water transport in the xylem.

\section{F. Molecular analyses}

The bacterial colonies associated with the fungal hyphae in PDA plates were carefully isolated, single-colony purified and individual colonies identified using PCR. Molecular analyses (Fig. 4 d) indicated three specific bacteria viz., Pseudomonas fluorescens, Stenotrophomonas maltophila, and Paenibacillus polymyxa to be the ectosymbionts found on the hyphae of wilt causal Fusarium oxysporum wild types in healthy looking plants (Fig $4 \mathrm{~F}, \mathrm{G}$ ) but these ectosymbionts were absent in Fusarium hyphae of wilt disease affected field zone (Fig. 4 e). The ectosymbiont bacterium attached to the fungal hyphal surface may have also its own circadian clock mechanisms, in which bacterial cell signalling systems that detect blue photons within the visible light spectrum via a class of flavin-binding photosensors known as Light, Oxygen, Voltage (LOV) domains [20]. In covered soils, particularly just beneath the proximal top surface, such circadian factors can be expected to regulate the growth, reproduction cycles in a different manner to those of 
uncovered soils. In our study, the inoculant bacteria (Paenibacillus spp) agent appears to have acted as a biological control agent [21] and unsuspectingly via apparent selective attachment to the hyphae as ectosymbionts may have possibly promoted "virulence silencing mechanisms" in F. oxysporum [e.g. 22].

We have summarised an overview of our present study (Fig. 4 e-h) and its visual impacts. Light manipulation in horticulture crops using variable wavelength lighting is increasing interest within the horticulture business and industry [23]. The light regulation of metabolic pathways of fungi is now a major carrier of adaptation signalling information [24] for their interactions with host cells. To this end, light sensing is crucial to host plant and the fungi it interacts with as well as the bacteria that reside on the fungal hyphae, on account of the hyphal resident ectosymbiont bacterial secretion factors that are well documented to contribute to regulation of fungal pathogenicity and virulence mechanisms on host plants. Although not by any means complete, and requiring further studies employing in vivo molecular expression analyses, our soil covering operation manipulate light and temperature regimes and visibly (Fig. 4) influenced the outcome of pathogen-plant interactions. Plant stem / emerging roots interface establish holistic relationships with diverse microbial community in soil [25], nowadays known as "plant microbiome" i.e. total microbiota of plants [26] immensely impact the overall pathogen and disease control strategies. Given that, our results indicating that the soil covering promoted pathogen suppression via the healthy looking plants (Fig. $4 \mathrm{f}, \mathrm{g}$ ) offers a practicable tool to the challenge of transposing the science of physiological molecular plant pathology to a tangible biotechnological solution on the ground from a farmer's perspective.

\section{G. Impact of physiological factors (light, temperature) and microbial interventions}

Our combinatorial data upon microbiological, SEM and preliminary molecular analyses suggest that Paenibacillus polymyxa followed by Pseudomonas spp., to be the bacteria most frequently found attached to the Fusarium hyphae that penetrated the $M$ incana roots. In order to ascertain if these consortia of bacteria attached to fungal hyphae imposed any influence on the pathogenicity of Fusarium, the hyphae of bacteria were cured by repeated subculture on PDA supplemented with the antibiotic oxytetracycline $(250 \mu \mathrm{g}$ $/ \mathrm{ml}$ ) and SEM confirmed that they were rendered virulent by virtue of penetrating plant root cell structures (Fig. 4 b, c). Our data obtained on bacterial ectosymbionts of Fusarium oxysporum hyphae from the rhizosphere of the host plant $M$. incana concurs with those of previous research [e.g. 27] on alternative horticultural crops such as lettuce. This is in agreement with current knowledge that diverse bacteria inhabit as fungal hyphal symbionts over a diverse range of phylogenetic variations [28]. Complex mechanisms of antibiosis, circadian clock phenomena, overarching cell signal proteins, Type III secretions, exudates, metabolite exchange, chemotaxis, microbial cross-talking (quorum sensing), symbiotic, host pathogenicity/virulence determination [29] including Fusarium oxysporum, these fungi-bacteria symbiosis are not exclusive to specific hosts. This microbial warfare happen as a rule in the overall development of host-pathogenic relationships in horticulture crops. Our microbiological data suggests that when wilt Fusarium hyphae are predisposed to inoculant biocontrol agent (e.g. Paenibacillus polumyxa) via the dip and drench treatments, the apparent virulence regulation effects expected may well lead to enhanced biological control of wilt disease. Further studies on light dependent gene expression analyses using latest real-time molecular tools may be required to monitor this environmental sensory perception of MHPRZ on both pathogenicity (wilt causal agent) and the virulence regulation (imposed by ectosymbiont on phytopathogenic fungal hyphae) in covered / uncovered regimes.

\section{$H$. Effects of soil covering, thermal variations and influence on soil fungal populations}

Results based on microbiological observations such as colony colour and hyphal features in the PDA plate and subsequent molecular confirmatory assays of a doctoral thesis in our laboratory [30] indicated that both covered and uncovered flower growers' soil bed samples harbour Fusarium oxysporum, $F$. venenatum $F$. culmorum and $F$. equiseti as the main Fusaria (Table 2). The types of soil saprophytic fungi we identified corroborated other molecular investigations [31] to discriminate Fusarium spp. that are common soil inhabiting phytopathogens of small grain cereals, wheat and barley crops in Ireland soils [32]. The generic population density and their dynamics may also be attributed to the reduction of ambient temperature at both the surface and the top $2-5 \mathrm{~cm}$ soil depth following covering of the soil, compared to the uncovered treatments.

TABLE 2: PREVALENCE AND DISTRIBUTION OF FUSARIUM SPP AND HYPHAL ECTOSYMBIOTIC BACTERIAL COLONISERS IN MATHIOLA INCANA CULTIVATED POLY TUNNEL FIELD SOIL BEDS

\begin{tabular}{|c|c|c|c|c|}
\hline \multirow{2}{*}{$\begin{array}{l}\text { Fungi isolated and identified } \\
\text { from cut flower-bed soil }\end{array}$} & \multicolumn{4}{|c|}{$\begin{array}{c}\text { In vitro Fusarium oxysporum inhibition } \\
\text { (\% of inhibitory zone) }\end{array}$} \\
\hline & Control & F. oxysporum ${ }^{2}$ & F. oxysporum ${ }^{3}$ & F. oxysporum ${ }^{4}$ \\
\hline \multicolumn{5}{|c|}{${ }^{1}$ Fusarium spp } \\
\hline F. equiseti & 88.2 & 62.5 & 82.3 & 68.9 \\
\hline F. venenatum & 105.1 & 66.1 & 69.6 & 58.1 \\
\hline F. culmorum & 98.6 & 79.9 & 89.6 & 86.7 \\
\hline \multicolumn{5}{|c|}{ Other native soil fungi ${ }^{5}$} \\
\hline Gliocadium spp & 101.6 & 43.3 & 54.0 & 47.0 \\
\hline Clonostachys rosea & 104.6 & 67.9 & 58.2 & 38.2 \\
\hline Eurotiomyces spp & 103.2 & 38.5 & 60.7 & 43.7 \\
\hline Trichoderma citrinoviride & 101.0 & 35.0 & 52.8 & 56.4 \\
\hline Trichoderma atroviride & 101.0 & 35.0 & 52.8 & 56.4 \\
\hline Clonostachys pseudochrolueca & 98.6 & 27.9 & 29.6 & 36.7 \\
\hline
\end{tabular}


The native Fusarium spp. populations exhibited ca. $\sim 2.0 \mathrm{x}$ $10^{4}$ colony forming units (CFUs) $\mathrm{g}^{-1}$ of either covered or uncovered soils that were widely prevalent in the Northern Ireland polytunnel floriculture soil-bed. The wilt causal fungi Fusarium oxysporum (wild types) occurred at a higher population density of $2.4 \times 10^{5} \mathrm{CFUs} \mathrm{g}^{-1}$ in uncovered soils, and there was a marked reduction of two $\log _{10}$ folds to $3.4 \mathrm{x}$ $10^{3} \mathrm{CFUs} \mathrm{g}^{-1}$ when the soils were covered by polythene. Nonpathogenic $F$. oxysporum isolates commonly occur in the soil as saprophytes, while some have been identified as biocontrol agents and endophytes [33].

I. Soil as a natural reservoir for non-pathogenic fungal antagonists against wilt Fusarium

In this present study, it was intriguing to note the widespread prevalence of a natural reservoir of other fungal antagonists (Table 2) such as Trichoderma atroviride formerly T. harzianum [34], T. citrinoviride, Eurotiomyces spp., Clonostachys pseudochrolueca [35] which possess inhibitory potential towards Fusarium populations. Some of the above fungal-fungal antagonists are registered as commercial formulations in Europe [36] as wilt fungal disease suppressants. In vitro inhibitory assay (Table 3) revealed that the Fusarium spp achieved a moderate ( 20\%) suppression of local wilt causal isolates of $F$. oxysporum, while other fellow native soil fungi (Gliocadium,
Chlonostachys and Trichoderma species) in the soils were significantly stronger $(>60 \%)$ inhibitors of the local flower wilt Fusaria. Wilt antagonistic fungi [Trichoderma atroviride, T. citrinoviride, Eurotiomyces spp., Clonostachys pseudochrolueca] increased by at least $1.0 \times \log _{10}$ fold from ca $<1.0 \times 10^{2} \mathrm{CFUs} \mathrm{g}^{-1}$ in uncovered soils to $\sim 3.2 \times 10^{3} \mathrm{CFUs}$ $\mathrm{g}^{-1}$ when covered with polythene sheets. Such small but significant $(\mathrm{p}=0.01)$ shifts in fungal population densities were noticeable after physiological manipulation of covering the soil than their counterpart uncovered soil plots which exhibited lower abundance of co-colonising wilt antagonistic fungal populations. The soil covering operation in our study is quite encouraging in respect of the same serving as a natural means of supplementing the biological agents commonly used for suppression of wilt disease and offers low cost biosecurity options for the cut-flower growing rural entrepreneurs in challenging competitive farming markets for Ireland within Europe. Our findings that varying environmental conditions and thereby enhancing the prospects of non-pathogenic natural biological control fungal agents inhabitants in soil themselves for suppression of Fusarium wilt diseases concurs in some respects with previous attempts to manipulate cropping conditions, soil type and Fusarium oxysporum inhibitory fungi [37], and as alternative disease management strategy in greenhouses for control of Fusarium wilt of tomato [38].

TABLE 3: FUNGAL - FUNGAL ANTAGONISM BETWEEN NATIVE SOIL FUNGI VERSUS WILD TYPE $F$. OXYSPORUM ISOLATES

\begin{tabular}{|c|c|c|c|}
\hline \multirow{3}{*}{$\begin{array}{l}\text { Fungi isolated and identified from } \\
\text { cut flower-bed soil }\end{array}$} & \multicolumn{2}{|c|}{ Fusarium spp population $\left(\mathrm{gm}^{-1}\right.$ soil $)$} & \multirow{3}{*}{$\begin{array}{l}\text { Bacterial Hyphae colonisation } \\
\text { (EM, culture/PCR) }\end{array}$} \\
\hline & Uncovered & Covered & \\
\hline & Start of trial & End of trial & \\
\hline \multicolumn{4}{|l|}{ Fusarium species } \\
\hline F. equiseti & $2.1 \times 10^{4}$ & $2.2 \times 10^{4}$ & \multirow{3}{*}{$\begin{array}{l}\text { Non-specific, variant bacteria } \\
\text { (e.g. Bacillus spp; Serratia spp) }\end{array}$} \\
\hline F. venenatum & & & \\
\hline F. culmorum & & & \\
\hline & & & \multirow{5}{*}{$\begin{array}{c}\text { Specific, native bacteria: } \\
\text { Pseudomonas flourescens, } \\
\text { Stenotrophomonas maltophila, } \\
\text { Paenibacillus polymyxa } \\
\text { Not tested }\end{array}$} \\
\hline Wilt causal agent & $2.4 \times 10^{5}$ & $3.4 \times 10^{3}$ & \\
\hline F. oxysporum (wild types) & & & \\
\hline Significant other fungi & $<1.0 \times 10^{2}$ & $3.2 \times 10^{2}$ & \\
\hline Trichoderma atroviride & & & \\
\hline Clonostachys pseudochrolueca & $<1.0 \times 10^{2}$ & $1.8 \times 10^{2}$ & Not tested \\
\hline
\end{tabular}

\section{J. Rotational lettuce cropping, phytosanitation and their impact on Fusarium Wilt}

The flower growers' field soils in Northern Ireland have a planting history involving both ornamental and lettuce crops and provided us with the opportunity to investigate wilt causing Fusarium populations involving both hosts regardless of the soil covering operations. Interestingly we found that local growers who were alternating crops of M.incana with winter lettuce Lactuca sativa, did not find visible symptoms of lettuce wilt caused by $F$. oxysporum f.sp. lactucae, This observation was in sharp contrast to the recent findings of lettuce field crop trials $[39,40]$ on severe Fusarium wilt caused by Fusarium oxysporum f.sp. lactucae in England and Europe. This phytopathogen was not detected by either plating on PDA or by PCR assays for genetic marker [41], sequence alignment comparisons of the same in our soils (unpublished data). This indicates that the wilt causal Fusarium populations surrounding the $M$. incana hosts may have been quite distinctive pathovars from those of the virulent, notorious $F$. oxysporum $\mathrm{f}$. sp race 4 [42], and thus most likely to be of native in origin, confined to the local Northern Ireland soils within the island of Ireland. Our molecular analyses (Fig 4 D) concurred with the conclusions of another study in Northern Italy in that, the Italian researchers seminal work [43] and later using molecular characterization [44] through IGS sequencing demonstrated that the forma specialis matthioli (ATCC16602 and ATCC16603) were not pathogenic on lamb's lettuce and isolates of different origins differed genetically from isolates that were poorly, moderately or highly virulent.

Due to the fact that both lettuce and cut flower picking involves phytosanitory considerations, transfer of infested soil through trays, pallets and the foot wear of farm workers has been confirmed as the main route that the disease lettuce Fusarium wilt as well those encountered in cut flower wilts are spread. In another study in Florida, researchers [45] found that due to the limitations of land availability for fallowing and rotation, cut flower growers have to contend with a number of other soil-borne wilt causal agents viz., Pythium and Rhizoctonia apart from Fusarium menace. These phytopathogenic species are present throughout their 
cultivation cycles in the year and are unresponsive to routine soil sterilisation. However, given that in our study, the grower had imposed stringent soil disinfection measures, as well as covering the soil with polythene sheets, the impact of the intercropping and human foot spread of Fusarium wilt may be subdued. Alternative biologically sustainable methods are increasingly becoming popular with farmers such as corn crop liquor [46] for lettuce root rot, new range of biostimulants also known as 'bioeffectors' [47], [48] comprising plant growth promoting, pathogen controlling bacteria, fungi and processed macroalgae extracts for crop management to reduce increasing climate change driven abiotic \& biotic stresses [47], [48].

\section{CONCLUSION}

Fundamental molecular mechanisms of saprophytic fungal spore adaptation, growth physiology and host pathogenicity are innate fungal behaviours. To translate this science and transfer the knowledge into 'practicable biotechnological solutions' for ornamental (cut flower) crops disease management by farmers is a challenge for agricultural scientists. To this end, our present work demonstrated simple agricultural practices such as physiological manipulation of temperature and light via covering of soil and interactive use of an enrichment compendium of native microbe as biocontrol agents themselves isolated from the disease prone soils for poly tunnel farming offer plausible solution to horticulturists. Our results also indicate the sustainable potential interventions to increase the resilience of horticulture and floriculture crops against recurrent persistent soil inhabiting pathogen opportunism and infection control.

\section{ACKNOWLEDGMENT}

We thank the consortium of flower growers led by $\mathrm{Mr}$. Shane Donnelly, Greenisland Flowers, Portadown, Co. Armagh, Northern Ireland, BT62 1XB, College of Agriculture, Food and Rural Enterprise (CAFRE), Greenmount, Co. Antrim, Northern Ireland and the Department of Agriculture, Environment and Rural Affairs (DAERA) directed Evidence and Innovation project 16/3/11, and the support of a EU FP7-BIOFECTOR grant (JRR, CF, TM) for this study. Author DN thanks his employers AFBI, DAERA for facilitating his research contributions in this study towards his $\mathrm{PhD}$ dissertation writing in part fulfilment at the University of Ulster. Authors also owe a sincere thanks to Graham McCollum (retired from service at AFBI, DAERA) for his contribution during the field trials, sampling, glasshouse research and his invaluable input to the graphics and cartoon illustrations used in this study.

\section{FUNDING}

This research work was supported by the Department of Agriculture, Environment and Rural Affairs (DAERA) Northern Ireland, UK via an Evidence and Innovation project 16/3/11, and the EU FP7-BIOFECTOR Grant Agreement No. 312117, administered at the authors laboratories, AgriFood \& Biosciences Institute (AFBI) (www.afbini.gov.uk).

\section{ETHICAL APPROVAL}

This article does not contain any studies with human participants or animals performed by any of the authors.

\section{REFERENCES}

[1] Vágány, V. 2012. Characterisation of Fusarium pathogens in the UK $\mathrm{PhD}$ Thesis. School of Life Sciences. University of Warwick, UK.

[2] Belanger, R. R., 2006. Controlling disease without fungicides: a new chemical warfare. Canadian Journal of Pathology 28 (Suppl.): 233238.

[3] Alabouvette C., Steinberg. C., 2006. The soil as a reservoir for antagonists to plant diseases. In: J. Eilenberg, Hokkanen, H. M. T., (eds.). An ecological and societal approach to biological control pp. 123-144. Dordrecht, the Netherlands Springer.

[4] Tian X., Zheng, Y., 2013. Evaluation of biological control agents for Fusarium wilt in Hiemalis begonia. Canadian Journal of Plant Pathology 35: 363-370.

[5] Tsuchiya, N. 2009. 'Chouya No. 37', a Fusarium Root Rot (Race 2)Resistant Lettuce. Journal of Japanese Society of Horticultural Science 78: 206-10.

[6] Anon., 2012. Personal communications, College of Agriculture, Food and Rural Enterprise (CAFRE), www.cafre.ac.uk, Greenmount, Co. Antrim, Northern Ireland, and the Department of Agriculture and Rural Development (DARD) www.dardni.gov.uk

[7] Ruiz-Roldán M.C., Garre, V., Guarro, J., Mariné, M. Roncero, M. I. 2008. Role of the White Collar 1 photoreceptor in carotenogenesis UV resistance, hydrophobicity, and virulence of Fusarium oxysporum Eukaryotic Cell 7:1227-1230.

[8] Liu, Y., Bell-Pedersen, D., 2006. Circadian Rhythms in Neurospora crassa and other filamentous fungi. Eukaryotic Cell 5: 1184-1193.

[9] Salichos, L., Rokas, A.2010. The diversity and evolution of circadian clock proteins in fungi. Mycologia 102: 269-278.

[10] Murayama, M., Maeda, Y., Rao, J.R., Matsuda, M., Moore, P. J. A., Millar, B. C., Rooney, P. J., Loughrey, A., Goldsmith, C. E., McDowell D., Moore, J. E.. 2010. Molecular identification of airborne bacteria associated with aerial spraying of bovine slurry waste employing $16 \mathrm{~S}$ rRNA gene PCR and gene sequencing techniques. Ecotoxicology and Environmental Safety, 73:443-447.

[11] Moore, J. E., McCollum, G., Murphy, A., Millar, B. C., Nelson, D. W A., Goldsmith, C. E., Rooney, P. J., Loughrey, A., Rao, J. R., 2010 Description of a simple bio-imaging technique to assess inhibition/growth promoting properties of novel agents on moulds. British Journal of Biomedical Science 67: 145-146.

[12] Gardiner, D., 1987. Symptom enhancement of Fusarium wilt of Chrysanthemum by high temperatures. Plant Disease 71: 1106-1109.

[13] Castrillo, M., García-Martínez, J., Avalos. J., 2013. Light-dependent functions of the Fusarium fujikuroi cryD DASH cryptochrome in development and secondary metabolism. Applied and Environmental Microbiology 79: 2777-2788.

[14] Fuller, K. K., Ringelberg, C. S., Loros, J. J., Dunlap, J. C., 2013. The fungal pathogen Aspergillus fumigatus regulates growth, metabolism, and stress resistance in response to light. mBio 4:142-155 (doi:10.1128/mBio.00142-13).

[15] Englander, L., Browning M., Tooley, P. W., 2006. Growth and sporulation of Phytophthora ramorum in vitro in response to temperature and light. Mycologia, 98: 365-373.

[16] Kuz'niak, E., 2001. Effect of fusaric acid on reactive oxygen species and antioxidants in tomato cell cultures. Journal of Phytopathology 149: $575-582$

[17] Rodriguez-Romero, J., Hedtke, M., Kastner, C., Muller, S., Fischer, R., 2010. Fungi, hidden in soil or up in the air: Light makes a difference. Annual Review of Microbiology 64:585-610.

[18] Nelson, D. W. V. A., Beattie, K., McCollum, G., Martin, T., Sharma, H. S. S., Rao, J. R., 2014. Performance of natural antagonists and commercial microbiocides towards in vitro suppression of flower bed soil-borne Fusarium oxysporum. Advances in Microbiology 4: 151159 .

[19] Gapillout, I., Milat M. L., Blein. J. P., 1995. Effect of fusaric acid on cells from tomato cultivars resistant or susceptible to Fusarium oxysporum f. sp. lycopersici. European Journal of Plant Pathology 102: 127-132.

[20] Herrou, J., Crosson, S., 2012. Function, structure, and mechanism in bacterial photosensory LOV proteins. Nature Reviews Microbiology 9 : 713-723. 
[21] Lounaci, L. Guemouri-Athmani,S., Boureghdea, H., Acouak, W., Heulin,T., 2016. Suppression of crown and root rot of wheat by the rhizobacterium Paenibacillus polymyxa. Phytopathologia Mediterranea 55: 355-365.

[22] Minerdi, D., Moretti, M., Gilardi, G., Barberio, C., Gullino, M. L., Garibaldi, A., 2008. Bacterial ectosymbionts and virulence silencing in a Fusarium oxysporum strain. Environmental Microbiology 10: 17251741.

[23] Anon., 2016. "Manipulating Light for Horticulture". A horticulture event held by Agriculture and Horticulture Development Board (AHDB), UK on 19 January 2016 at Stoneleigh Park, Warwickshire, UK. https://horticulture.ahdb.org.uk/event/manipulating-lighthorticulture.

[24] Tisch, D and M. Schmoll. 2010. Light regulation of metabolic pathways in fungi. Applied Microbiology and Biotechnology 85: 12591277.

[25] Steele H., Streit, W. R., 2006. Metagenomics for the study of soil microbial communities. In: Cooper, J. E., Rao, J. R., (eds.). Molecular Approaches to Soil, Rhizosphere and Plant Microorganism Analysis, pp. 42-54. CABI www.cabi.org Oxfordshire, UK

[26] Santhanam, R., Luu, V. T., Weinhold, A., Goldberg, J., Oh, Y. Baldwin, I. T., 2015. Native root-associated bacteria rescue a plan from a sudden-wilt disease that emerged during continuous cropping. Proceedings of the National Academy of Science (PNAS, USA) 112 5013-5020

[27] Minerdi, D., Bossi, S., Maffei, M. E., Gullino M. L., Garibaldi, A. 2011. Fusarium oxysporum and its bacterial consortium promote lettuce growth and expansin A5gene expression through microbial volatile organic compound (MVOC) emission. Federation of European Microbiology Societies (FEMS) Microbiology Ecology 76: 342-351.

[28] Hoffman M. T., Arnold, A. E., 2010. Diverse bacteria inhabit living hyphae of phylogenetically diverse fungal endophytes. Applied Environmental Microbiology 76: 4063-4075.

[29] Frey-Klett, P., Burlinson, P., Deveau, A., Barret, M., Tarkka, M. Sarniguet, A., 2010. Bacterial-fungal interactions: hyphens between agricultural, clinical, environmental, and food microbiologists. Microbiol. Molecular Biology Reviews 75: 583-609.

[30] Nelson, D. W. V. A., 2017. Antimicrobials: Novel insights into plan health and biomedical applications. PhD Thesis. University of Ulster, Northern Ireland, U.K.

[31] Lievens, B., Rep M., Thomma. P. H. J. B., 2008. Recent development in the molecular discrimination of formae speciales of Fusarium oxysporum. Pest Management Science 64: 781-788.

[32] Doohan F. M., Brennan J. M., Cooke, B. M., 2003. Influence of climatic factors on Fusarium species pathogenic to cereals. European Journal of Plant Pathology 109: 755-768.

[33] Alvindia, D. G., Hirooka. Y., 2015. Identification of Clonostachys and Trichoderma spp. from banana fruit surfaces by cultural, morphological and molecular methods. Mycology 2:109-115.

[34] Anon., 2008. Review report for the active substance Trichoderma atroviride (formerly T. harzianum) T-11. Article 4 (1) (b) (iv) and (v) of Directive 91/414/EEC. https://www.paneurope.info/old/Campaigns/pesticides/documents/loopholes/Directive \%2091-414.pdf

[35] Alabouvette, C., Olivain, C., Migheli Q., Steinberg. C., 2009 Microbiological control of soil-borne phytopathogenic fungi with special emphasis on wilt-inducing Fusarium oxysporum. New Phytology 184: 529-544.

[36] Ndiaye, M., Termorshuizen A. J., van Bruggen, A. H. C., 2010. Effects of compost amendment and the biological control agent Chlonostachys rosea on the development of charcoal rot (Macrophomina phaseolina) on cowpea. Journal of Plant Pathology 92: 173-180.

[37] Armstrong, G. M., Armstrong. J. K., 1981. Formae specialis and races of Fusarium oxysporum causing wilt diseases. In: Nelson, P. E., Toussoun T. A., Cook R. J., (eds.). Fusarium Diseases, Biology, and Taxonomy pp. 391-399. Pennsylvania State University Press.

[38] Larkin R. P., Fravel, D. R., 2002. Effects of varying environmental conditions on biological control of Fusarium wilt of tomato by nonpathogenic Fusarium spp. Phytopathology 92:1160-1166.

[39] Taylor, A., 2018. Technical review on lettuce Fusarium wilt, caused by Fusarium oxysporum f. sp. lactucae. Final Report, SCEPTREplus Project, February 2018, Agriculture and Horticulture Development Board (AHDB), UK https://horticulture.ahdb.org.uk/

[40] Taylor, A., Vágány, V., Jackson, A. C., Harrison, R. J., Rainoni, A. Clarkson, J. P., (2016). Identification of pathogenicity-related genes in Fusarium oxysporum f. sp. cepae. Molecular Plant Pathology 17: 1032-47.
[41] Aruga, D., Tsuchiya, N., Matsumura, H., Matsumoto, E., Hayashida, N., 2012. Analysis of RAPD and AFLP markers linked to resistance to Fusarium oxysporum f. sp lactucae race 2 in lettuce (Lactuca sativa L.). Euphytica 187: 1-9.

[42] Fujinaga, M., Ogiso, H., Tuchiya, N., Saito, H., Yamanaka, S., Nozue, M., Kojima, M., 2003. Race 3, a new race of Fusarium oxysporum $\mathrm{f}$ sp. lactucae determined by a differential system with commercial cultivars. Journal of General Plant Pathology 69: 23-28.

[43] Garibaldi, A., Gilardi, G., Gullino. M. L., 2002. First report of Fusarium oxysporum on lettuce in Europe. Plant Disease 86: 1052.

[44] Srinivasan, K., Gilardi, G., Spadaro, D., Gullino, M. L., Garibaldi, A., 2010. Molecular characterization through IGS sequencing of formae speciales of Fusarium oxysporum pathogenic on lamb's lettuce. Phytopathol. Mediterr. (2010) 49, 309-320.

[45] Malek, E. R., Wang, K-H., McSorley, R., 2005. Effect of naturally occurring fungal pathogens from a cut flower production site on four cut flower species, Proceedings Florida State Horticulture Society 118 306-309.

[46] Chinta, Y. D., Kano, K., Widiastuti, A., Fukahori, M., Kawasaki, S. Eguchi, Y., Misu, H., Odani, H., Zhou, S. Y., Narisawa, K., Fujiwara, K., Shinohara, M., Sato, T., 2014. Effect of corn steep liquor on lettuce root rot (Fusarium oxysporum f. sp lactucae) in hydroponic cultures. Journal of Science of Food and Agriculture 94: 2317-23.

[47] Sharma, H. S. S., Selby, C., Fleming, C., Rao, J. R., Martin, T., 2014 Plant biostimulants: a review on the processing of macroalgae and use of extracts for crop management to reduce abiotic \& biotic stresses. Journal of Applied Phycology 26: 465-490.

[48] Sharma, H. S. S., Selby, C., Carmichael, E., McRoberts, C., Rao, J. R., P. Ambrosino, Chiurazzi, M., Pucci, M., Martin, T., 2016. Physicochemical analyses of plant biostimulant formulations and characterisation of commercial products by instrumental techniques. Chemical and Biological Technologies in Agriculture. 3: 1-17.

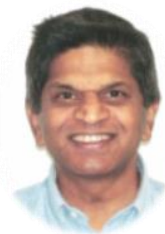

Professor JR Rao, BSc, MSc (Ag Microbiology), PhD (UK). Plant microbiologist experience in soil biology, bacterial, fungal and viral research. Principal Investigator on DAERA projects and EUFP7 biofector (biostimulant for crop improvement), alternative pesticide active microbiological sources for pest and disease control. Research expertise also includes Plant Growth Promoting Rhizobacteria (grassland legume clover - Rhizobium molecular interactions, horticulture (e.g. Fusarium wilt), forest plant health (e.g. die-back diseases), antibiotic resistance, farm waste recycling, Cryptosporidium (safefood co-ordinator), published over 100+ publications, holds twinned Professor titles at QUB and UU. Citations H index 13; RG Score 37.13.

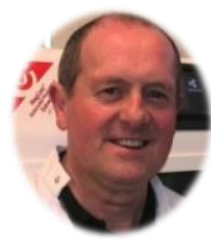

Dr Colin Fleming BSc (Hons), PhD (Zoology, UK) (AFBI): Principle Scientific Officer AFBI, Belfast and Senior Lecturer in the Institute of Global Food Security, the Queens University of Belfast. Head of Plant Health, Pathogen \& Pest Surveillance, Diagnostics Services to the Department of Agriculture, Environment and Rural Affairs (DAERA), Northern Ireland and to DAERA's Plant Health Policy Branch listed commercial customers for undertaking epidemiological work on emerging threats to the local environment i.e. Phytophthora species, ash dieback (Hymenoscyphus fraxineus) and root knot (Meloidogyne) nematodes, field assessments of biostimulant efficacy to reduce abiotic and biotic stress in crops and turfgrass / molecular biology and gene expression analysis. Consultant to agriculture ministry UK, Ireland, EU and amenity sectors.

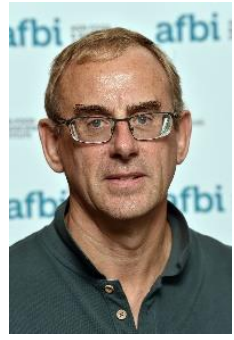

Mr Trevor Martin is a project leader (Nematology extensive specialist expertise on glasshouse, polytunnel field biology experimental plots and facilities, bio-control of soil pathogens, potato cys nematodes, pest diagnostics, crop protection and quarantine pathology. 


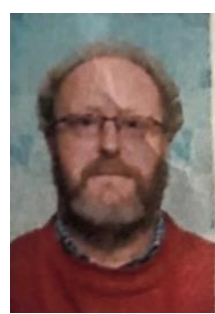

Dr David Nelson (AFBI) BSc Hons (Botany), $\mathrm{PhD}$

in Antimicrobials, (2017). Scientific Officer, AFBI,

$35+$ years of experience in botany, plant tissue culture

and micropropagation, and plant microbiology. 